\title{
IDENTIFICATION OF A RABID DOG ILLEGALLY INTRODUCED FROM the Republic of the Gambia to Belgium and France
}

\author{
The French* and Belgian** multidisciplinary investigation teams (v.vaillant@invs.sante.fr)
}

\section{Background}

In March 2008, a six-month-old stray female puppy was found injured in the Republic of the Gambia. A Belgian resident holidaying in the country took the dog to a local veterinary clinic to be treated. It was operated upon, and on 15 March was given a first rabies vaccine dose and micro-chipped. The dog was adopted by the Belgian woman, and a certificate of good health was provided for it by a Gambian veterinarian on 5 April. The dog and its new owner took a flight to Belgium on 6 April and arrived in Brussels, via Dakar, on the morning of 7 April. No serological control had been carried out before leaving hte Republic of the Gambia, and the owner had not applied for legal authorisation to import the dog into Belgium. The dog travelled in the cabin inside a travel box carried on the owner's lap, with just the head exposed. The dog had been sedated before departure and reportedly slept throughout the plane journey. According to the owner, there were two possible human contacts during the flight.

The dog was taken to a veterinary clinic in Brussels on 8 April to be treated for a necrotic wound (possibly a bite). There was no other animal or human in the practice at the time. The dog could not walk properly, so it was walked around a nearby square a few times, for a short period. There was no contact with other animals.

On 12 April, the owner left the dog with an acquaintance in Brussels for several hours. That person had two cats, but these never came close to the dog as they were afraid of it. The cats were not immunised against rabies.

On 13 April, the owner drove to the Var district of France, without stopping anywhere else in Belgium, taking the dog with her. The dog had no contact with other humans or animals on the trip. During the stay in the Var district, the dog did not leave its owner's garden.

The dog presented with the first symptoms of rabies on 16 April and was examined in several veterinary clinics, before dying in one of them on 21 April. A diagnosis of rabies was laboratory-confirmed on 24 April by the National Reference Centre for Rabies at the Institut Pasteur in Paris, France. The diagnosis was confirmed by direct immunofluorescence and by the isolation of the virus in tissue culture. The detection of viral RNA by RT-PCR was also positive. The typing of the virus, carried out by partial sequencing of the gene of the viral nucleoprotein, showed it to be a lyssavirus genotype 1 (rabies virus), African II lineage, originating from Western Africa and very similar to strains circulating in Guinea and Sierra Leone.

\section{Control measures}

A risk assessment was carried out by the appropriate stakeholders in Belgium on 25 April. The at-risk period for transmission was estimated to be from 1 April (the estimated start date of virus excretion according to a hypothesis of 15 days of asymptomatic salivary excretion) to $21 \mathrm{April}$ (date of death). A list of individuals and animals that had possibly come into contact with the rabid dog in France, Belgium and the Republic of the Gambia from 1 April was constructed by questioning the dog-owner and staff at the veterinary clinics in which the dog had been treated. The dog had difficulty in moving around following the surgical interventions on its wound and had a very limited number of contacts with other animals and humans. Nineteen persons who had been in contact with the dog are being administered with anti-rabies treatment. The following measures were also taken in Belgium:

- An active tracing of people and animals in contact with the puppy was carried out. Persons and owners of animals that had close contact with the dog were informed, assessed by local and federal animal and personal health agencies and vaccinated if necessary. This included the owner, two passengers who were sitting in the same row as her, the staff on board the aeroplane, the Belgian veterinarian and his staff, and the friends of the owner in Brussels: in total, 13 persons in Belgium;

- In accordance with Belgium's sanitary police legislation, information and warning posters were displayed by the administrative authorities and districts concerned;

- A press release was issued, giving appropriate information to the public and with a reminder that the regulations in the European Union and Belgian regulations on pet vaccination and import should be followed;

- Contact with the veterinarian and human health authorities in Republic of the Gambia is in process so that appropriate measures can be applied to the persons who were in close contact with the dog in Belgium.

\section{Conclusions}

In this event, the people at risk and the times at which they were at risk were relatively clear. Possible human and animal contacts with the dog and the travel itineraries in France and Belgium are known to the French and Belgium health and veterinary authorities and appropriate prevention and control measures have been taken. The risk to people other than those already identified by contact tracing is considered to be low.

The risk to passengers on the plane is also considered to be low, as the owner is aware of no contacts with the dog during the plane journey. There is currently no evidence of a transmission 
chain in France or Belgium among domestic animals as a result of this event.

The delay between the vaccination of this dog and its entry into Belgium and then France did not conform to the delay of one month required by these countries. The criterion of having had a rabies antibody titre three months before entry into these countries was also not met for this particular dog.

* The French investigation team:

M Auzet-Caillaud, Direction départementale des affaires sanitaires et sociales (Ddass)

du Var

P Botella, Ddass du Var

H Bourrhy, Centre national de référence (CNR) de la rage

R Bovet, Ddass du Var

L Bouteiller, Direction générale de l'alimentation (DGAl)

J Chemardin, Direction générale de la santé (DGS)

A Chemel, Direction départementale des services vétérinaires (DDSV) du Var

L Dacheux, CNR de la rage

0 Debaere, DGAL

I Capek, Institut de veille sanitaire (InVS)

M Goudal, Centre antirabique, Institut Pasteur Paris

J Maslin, Centre anti-rabique de l'Hôpital d'instruction des armées, St Anne de Toulon

A Simon, DDSV du Var

V Vaillant, InVS

** The Belgian investigation team:

J Bots, J Waegenaere, Medical inspectorate, Brussels Region, Brussels

D Wagner, D Reynders, W D'Hooghe, Federal Public Service of Public Health, Food Chain Safety and Environment, Brussels

P Houdart, JM Dochy, Food Chain Safety Agency, Brussels

$S$ Maes, Public Health Institute, Brussels

I Le Roux, Pasteur Institute, Brussels

This article was published on 30 April 2008.

Citation style for this article: The French ${ }^{\star}$ and Belgian ${ }^{\star *}$ multidisciplinary investigation teams. Identification of a rabid dog illegally introduced from the Republic of the Gambia to Belgium and France. Euro Surveill. 2008;13(18):pii=18856. Available online: http://www.eurosurveillance.org/ViewArticle. aspx?ArticleId=18856 